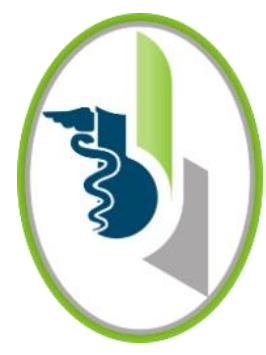

ACCESO 2 ABIERTO

Copyright: (C) 2020. Esta es una reseña bibliográfica de acceso abierto, distribuido bajo los términos de la licencia https://creativecommons.org/licenses/bync-sa/4.0/ la cual permite el uso sin restricciones, distribución y reproducción en cualquier medio, siempre y cuando el original, el autor y la fuente sean acreditados.

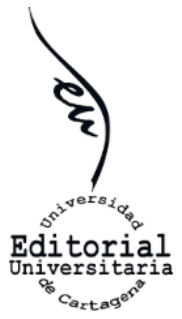

\section{Inflamación e identificación de blancos moleculares en la progresión del cáncer de próstata}

\author{
Inés Benedetti, Niradiz Reyes
}

Este libro está dirigido a estudiantes de pre y posgrado, investigadores en el campo de las ciencias básicas biomédicas, clínicos en el campo de la oncología, patología y urología, con interés en la asociación planteada entre inflamación crónica de la próstata y el adenocarcinoma prostático, así como en la búsqueda de posibles blancos moleculares en esta neoplasia.

El libro se ha dividido en dos secciones. La primera, revisa aspectos generales de la estructura anatómica e histológica de la glándula prostática, las características epidemiológicas y morfológicas del adenocarcinoma prostático, sus lesiones precursoras, el concepto de la transición epitelialmesenquimal en esta neoplasia, y su patogenia. Se revisa el estado actual

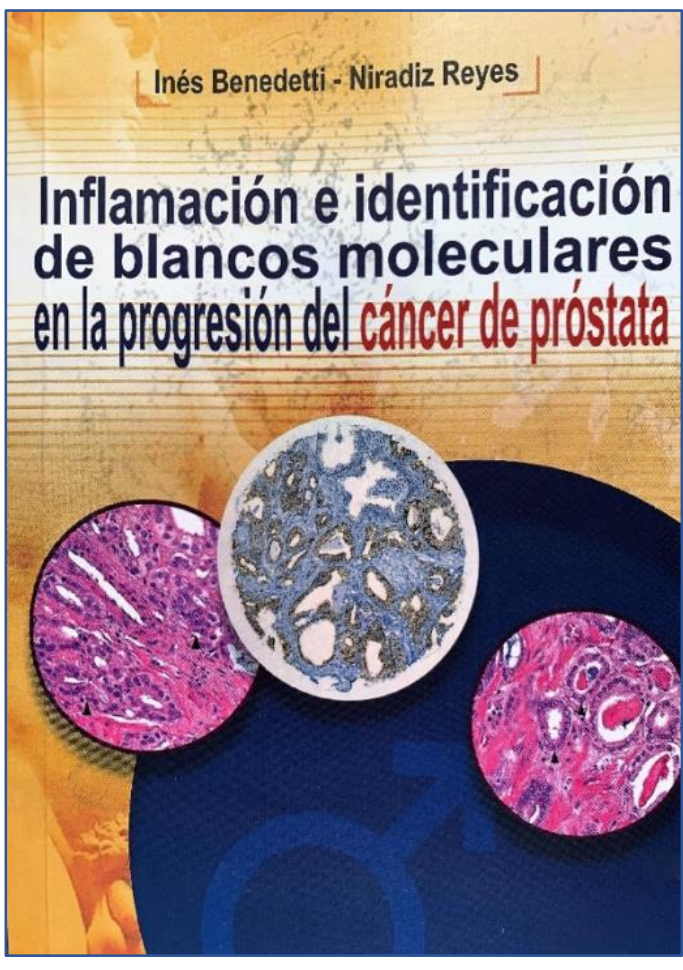
del conocimiento sobre la inflamación crónica de la próstata como uno de los factores ambientales potencialmente involucrados en la carcinogénesis prostática a los que se les ha dedicado mayor interés en la investigación en los últimos años.

En la segunda sección se presentan los resultados originales de investigación obtenidos dentro de las líneas de investigación Cáncer, y Factores Genéticos y Ambientales de Riesgo en Cáncer y Biomarcadores, desarrolladas por los grupos de investigación Histopatología y Genética y Biología Molecular, de la Facultad de Medicina de la Universidad de Cartagena, dirigidos por las autoras, relacionados con las temáticas descritas en la primera sección.

La doctora Inés Benedetti es Médica de la Universidad del Norte, Barranquilla, Colombia. Patóloga y Doctora en Ciencias Biomédicas de la Universidad de Cartagena, Colombia. Actualmente se desempeña como profesora, y directora del grupo de investigación Histopatología, de la facultad de Medicina de la Universidad de Cartagena, y editora de la Revista Ciencias Biomédicas.

La doctora Niradiz Reyes Ramos es Química Farmacéutica de la Universidad de Cartagena, Magíster y PhD en Microbiología e Inmunología del New York Medical College, Valhalla, NY, U.S.A. Actualmente se desempeña como profesora, y directora del grupo de investigación Genética y Biología Molecular, de la facultad de Medicina de la Universidad de Cartagena. 